\title{
INVESTIGAÇÃO DOS MATERIAIS UTILIZADOS COMO MATÉRIA-PRIMA NAS INDÚSTRIAS LOCALIZADAS EM ITATIBA E REGIÃO VISANDO MAIOR CONTEXTUALIZAÇÃO DOS CONTEÚDOS DA DISCIPLINA TECNOLOGIA DOS MATERIAIS E PROCESSOS DE FABRICAÇÃO DO CURSO ENGENHARIA DE PRODUÇÃO DA UNIVERSIDẢDE SÃO FRANCISCO
}

\author{
INVESTIGATION OF MATERIALS USED AS RAW MATERIALS IN THE \\ INDUSTRIES LOCATED IN ITATIBA AND REGION AIMING FOR GREATER \\ CONTEXTUALIZATION OF THE CONTENTS OF THE SUBJECT 'MATERIALS \\ TECHNOLOGY AND MANUFACTURING PROCESSES' OF THE PRODUCTION \\ ENGINEERING COURSE OF SÃO FRANCISCO UNIVERSITY
}

\author{
SILVA, Felipe ${ }^{1,2}$; PAIVA, Rafael ${ }^{1,2}$; CAVALARO, Felipe ${ }^{1,2}$, MARQUES, Elaine $^{2}$; \\ BIANCHI, Roberta ${ }^{1,2}$ \\ ${ }^{1}$ Grupo de Pesquisa em Meio Ambiente e Sustentabilidade (GPMAS) \\ ${ }^{2}$ Universidade São Francisco (USF) - Av. Sen. Lacerda Franco, 360 - Centro, \\ roberta.bianchi@usf.edu.br
}

\begin{abstract}
RESUMO. A sociedade faz uso de produtos de higiene, alimentação, medicação, cosméticos, entre outros, para satisfazer suas necessidades. Dessa forma, entender como os materiais podem ser classificados e manipulados para desenvolver produtos é de extrema importância. O papel do engenheiro é fundamental na fabricação de um determinado material, desde a concepção, o processo de fabricação e a aplicação. Nesse sentido, propõe nesse trabalho, identificar os principais materiais utilizados como matéria-prima nas indústrias localizadas em Itatiba e região a fim de correlacionar com as disciplinas Tecnologia dos Materiais e Processos de Fabricação. Para isso, o trabalho foi submetido ao Comitê de Ética da USF e aprovado sob o número CAAE: 55009616.4.0000.5514, inicialmente adotou-se como estratégia para o levantamento das informações, a aplicação de um questionário elaborado em conjunto entre os professores e alunos. O questionário foi aplicado por meio de uma plataforma web com login e senha. No entanto, essa estratégia não foi bem sucedida, apenas duas empresas participaram da pesquisa, esse fato pode estar relacionado com alguns fatores como, período inapropriado para aplicação do questionário, por ter sido realizado no final do ano, incerteza econômica, política e financeira do país, despreocupação com as questões ambientais, entre outros. Devido ao problema apresentado, mudou-se a abordagem para a obtenção das informações, o novo plano baseou-se na criação de um novo questionário e aplicado aos alunos do curso de Engenharia de Produção da Universidade São Francisco. Com essa mudança, houve um aumento significativo de respostas comparado à pesquisa anterior.
\end{abstract}

Palavras-chave: materiais, questionário, meio ambiente. 


\begin{abstract}
Society makes use of cleaning and feeding products, medications, cosmetics, among others, to satisfy their needs. This said, understanding how materials can be classified and manipulated to develop products is extremely important. The work of an engineer is essential in the manufacturing of a given material, from the design, to the process of manufacturing and application. In this way, the purpose of this job is to identify the main materials used as raw material in industries located in Itatiba and surroundings in order to correlate with the courses Materials Technology and Manufacturing Processes. In this regard, the work was submitted to the Ethics Committee of USF (University of São Francisco) and approved by the CAAE (Presentation Certificate to Ethics Appraisal) number: 55009616.4.0000.5514. Initially, the application of questionnaire elaborated jointly between students and professors was adopted to gather information. The questionnaire was applied via web platform with login and password. Unfortunately, this strategy wasn't successful, once only two companies took part in the survey. This could be explained by the fact that the survey was applied in the end of the year, when economic uncertainty and political problems were faced by the country. Based on that, a new strategy was incorporated in order to collect the necessary information for the research. The strategy included changes in the previous questionnaire and its application among engineering students from University of São Franscisco. The changes brought substantial changes to the results of the research, once there were many more answers.
\end{abstract}

Keywords: materials, questionnaire, environment.

\title{
INTRODUÇÃO
}

Materiais podem ser definidos como substâncias (ou mistura de substâncias) que possuem propriedades que as tornam úteis em produtos, dispositivos, estruturas e máquinas. São constituídos de átomos, e são estes que determinam se o material é um plástico, madeira ou metal é a estrutura geral do átomo que diferencia um material do outro (INTERRANTE e HAMPDEN-SMITH, 1998). Logo, nota-se que esta definição faz uma clara conexão entre materiais e aplicações. De fato, os materiais fazem parte da história do desenvolvimento da humanidade e estão intimamente ligados às habilidades em produzir e manipular materiais para satisfazer as necessidades. Antigamente, as civilizações foram designadas de acordo com o seu nível de desenvolvimento em relação aos materiais como sendo: Idade da Pedra e Idade dos Metais (CALLISTER, 2002; VAN-VLACK, 1984).

O desenvolvimento de novas tecnologias e a compreensão de um determinado tipo de material é com frequência o precursor para o desenvolvimento de novos materiais com propriedades desejadas e/ou superiores. Por exemplo, os automóveis não teriam sido possíveis se não existisse uma disponibilidade a baixo custo de aço ou de algum outro material substituto comparável. Ao longo do tempo, as indústrias automobilísticas estão usando o alumínio e o plástico no lugar do aço, a fim de diminuir o peso dos automóveis, o que melhora a eficiência do motor e reduz o consumo de combustível (CABRAL; MURPHY, 2010). Dispositivos eletrônicos sofisticados dependem de componentes fabricados a partir dos chamados materiais semicondutores (CIPRIANO et al., 2014). O uso de todo e qualquer tipo de material está associado ao seu tipo de processamento (indica a maneira como será fabricado o material). Por sua vez, para definir o tipo de processamento é necessário conhecer a estrutura do material (como a matéria está organizada atomicamente) que por sua vez, determina diretamente os tipos de propriedades. São as propriedades que determinam a aplicação do material, ou seja, no 
estudo e desenvolvimento de materiais, esses quatro itens estão diretamente relacionados e inter-relacionados com a Engenharia, Ciência dos Materiais e Tecnologia dos Materiais (Figura $1)$.

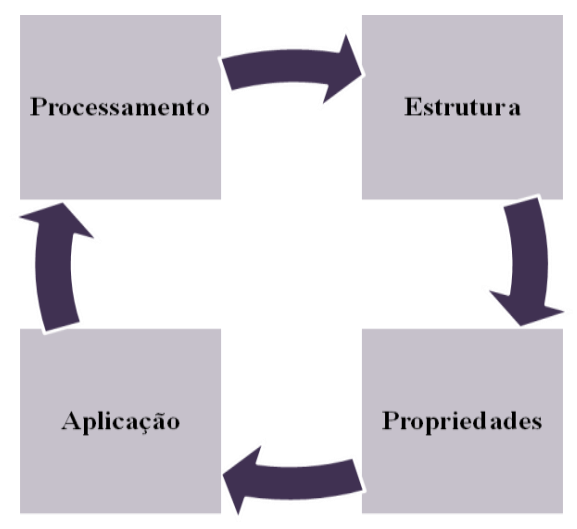

Figura 1 - Relação dos quatro itens para o estudo e desenvolvimento de materiais e a inter-relação com a Engenharia, Ciência dos Materiais e Tecnologia dos Materiais.

(Fonte: Próprio autor).

Para melhor compreensão acerca dos vários materiais existentes, a Tabela 1 apresenta a classificação dos materiais e algumas de suas respectivas propriedades. Observa-se que cada material têm suas características, no entanto, com o avanço da tecnologia e com o auxílio da nanotecnologia é possível criar e recriar inúmeras combinações de materiais a fim de obter as propriedades desejadas (CAO, 2004).

O Curso de Engenharia de Produção visa formar profissionais capacitados para projetar, implantar, operar, otimizar e manter sistemas produtivos integrados de bens e serviços que envolvam homens, materiais, tecnologia, informação e energia e que tenham conhecimentos e senso crítico para especificar, prever e avaliar os resultados obtidos destes sistemas para a sociedade e o meio ambiente, recorrendo a conhecimentos especializados da matemática, física, ciências humanas e sociais, conjuntamente com os princípios e métodos de análise e projeto da engenharia (PPC, 2011). Os currículos dos cursos de Engenharia deverão dar condições a seus egressos de adquirir competências e habilidades, que segundo o Artigo $4^{\circ}$ da Resolução CNE/CES 11/2002.

I - aplicar conhecimentos matemáticos, científicos, tecnológicos e instrumentais à engenharia;

II - projetar e conduzir experimentos e interpretar resultados;

III - conceber, projetar e analisar sistemas, produtos e processos;

IV - planejar, supervisionar, elaborar e coordenar projetos e serviços de engenharia;

$\mathrm{V}$ - identificar, formular e resolver problemas de engenharia;

VI - desenvolver e/ou utilizar novas ferramentas e técnicas;

VI - supervisionar a operação e a manutenção de sistemas;

VII - avaliar criticamente a operação e a manutenção de sistemas;

VIII - comunicar-se eficientemente nas formas escrita, oral e gráfica;

IX - atuar em equipes multidisciplinares;

$\mathrm{X}$ - compreender e aplicar a ética e responsabilidade profissionais;

XI - avaliar o impacto das atividades da engenharia no contexto social e ambiental;

XII - avaliar a viabilidade econômica de projetos de engenharia;

XIII - assumir a postura de permanente busca de atualização profissional (CNE.

Resolução CNE/CES 11/2002). 
Tabela 1 - Classificação dos materiais e principais características.

\begin{tabular}{|c|c|c|c|c|}
\hline \multicolumn{5}{|c|}{ Classificação } \\
\hline \multirow{3}{*}{$\begin{array}{c}\text { Materiais } \\
\text { tradicionais } \\
\text { Metais }\end{array}$} & \multicolumn{2}{|c|}{ Características } & \multirow{3}{*}{$\begin{array}{c}\text { Materiais } \\
\text { Avançados } \\
\text { Semicondutores } \\
\end{array}$} & \multirow[t]{2}{*}{ Características } \\
\hline & $\begin{array}{l}\text { Quanto ao tipo } \\
\text { de ligação }\end{array}$ & Propriedades & & \\
\hline & $\begin{array}{l}\text { Composto por } \\
\text { elementos } \\
\text { metálicos }\end{array}$ & $\begin{array}{l}\text { - Transparentes a } \\
\text { luz; } \\
\text { - Resistentes } \\
\text { deformáveis; }\end{array}$ & & $\begin{array}{l}\text { - Apresentam propriedades } \\
\text { elétricas intermediárias } \\
\text { entre condutores elétricos } \\
\text { (metais e ligas metálicas) e } \\
\text { os isolantes (cerâmicas e } \\
\text { polímeros). }\end{array}$ \\
\hline$\underline{\text { Cerâmicas }}$ & $\begin{array}{l}\text { Formado por } \\
\text { elementos } \\
\text { metálicos e não- } \\
\text { metálicos }\end{array}$ & $\begin{array}{l}\text { - Isolantes de calor } \\
\text { e eletricidade; } \\
\text { - Resistentes às } \\
\text { altas } \\
\text { temperaturas; } \\
\text { - São duras, porém, } \\
\text { frágeis; }\end{array}$ & $\underline{\text { Biomateriais }}$ & $\begin{array}{l}\text { - São materiais sintéticos, } \\
\text { naturais ou naturais } \\
\text { modificados, destinados a } \\
\text { estarem em contato e } \\
\text { interagir com o sistema } \\
\text { biológico. }\end{array}$ \\
\hline$\underline{\text { Polímeros }}$ & $\begin{array}{l}\text { Compostos } \\
\text { orgânicos } \\
\text { baseados em } \\
\text { carbono, } \\
\text { hidrogênio e } \\
\text { elementos não- } \\
\text { metálicos }\end{array}$ & $\begin{array}{l}\text { - Elastômeros } \\
\text { - Termoplástico; } \\
\text { - Termofixo; }\end{array}$ & $\underline{\text { Nanomateriais }}$ & $\begin{array}{l}\text { - Ciência que utiliza materiais } \\
\text { em escala nanométrica, } \\
\text { conhecida com a ciência dos } \\
\text { átomos; } \\
\text {-É capaz de manipular } \\
\text { átomos e moléculas; } \\
\text { - Aumento da área } \\
\text { superficial; }\end{array}$ \\
\hline Compósitos & $\begin{array}{c}\text { Composto por } \\
\text { dois (ou mais) } \\
\text { materiais. }\end{array}$ & $\begin{array}{l}\text { - Preservam as } \\
\text { propriedades } \\
\text { "boas" dos } \\
\text { componentes e } \\
\text { possuem } \\
\text { propriedades } \\
\text { superiores às de } \\
\text { cada componente } \\
\text { separado. }\end{array}$ & & \\
\hline
\end{tabular}

Fonte: Próprio autor

A disciplina Tecnologia dos Materiais tem como ementa os critérios de seleção dos materiais; Propriedades dos materiais; Seleção e sistematização dos processos de seleção de materiais; Resistência à corrosão dos materiais metálicos; Materiais para tratamentos superficiais; Projeto de seleção de materiais para sistemas mecânicos; Compósitos, polímeros e cerâmicos. Por sua vez, a disciplina Processos de Fabricação tem por objetivo transmitir aos estudantes uma visão geral dos principais processos de fabricação existentes, destacando suas características, campos de aplicação, problemas decorrentes de sua utilização e aspectos relacionados aos custos para que, ao final da disciplina, o estudante adquira conhecimentos e 
habilidade para reconhecer os processos que foram utilizados para a fabricação de determinada peça.

Nesse sentido, a cidade escolhida para o desenvolvimento desse trabalho foi Itatiba e Região, uma vez que o município faz parte da Região Metropolitana de Campinas, localizandose ao noroeste da capital do estado, estando a cerca de oitenta quilômetros desta. Sua população estimada em 2014 é de aproximadamente 111620 habitantes. A cidade é conhecida como "Princesa da Colina" devido ao seu relevo acidentado. É famosa também pela indústria de tecido, metalúrgica, química e de tecnologia de ponta. Segundo a Federação das Indústrias do Estado do Rio de Janeiro (FIRJAN), Itatiba, no ano de 2010, foi a terceira cidade com maior qualidade de vida do Brasil, apresentando um Índice FIRJAN de Desenvolvimento Municipal de 0,9276 (FIRJAM, 2010).

A cidade de Itatiba é chamada de Capital Brasileira do Móvel Colonial, em função das diversas indústrias do ramo moveleiro instaladas na cidade. Porém, com o tempo, a indústria tem se diversificado e produzido diversas modalidades de móveis. Outros setores têm alavancado a região, e muitas empresas vêm se instalando na cidade, que conta com um distrito industrial, bem como próximo à região. Entre as indústrias de renome instaladas em Itatiba, pode-se citar a Nívea e a Rhodia, entre outras. Há ainda a grande proximidade com outros centros industriais, tais como os que estão ao redor da cidade, como Jundiaí, Campinas, Valinhos, Vinhedo, Atibaia, Bragança Paulista entre outras que concentram grandes industriais dos mais variados ramos. Com esse grande rol de empresas na região, faz-se necessário entender os estágios que um produto acabado percorre, desde o lançamento até o declínio e consequentemente os futuros impactos ao mesmo ambiente

Todo produto, quando desenvolvido, leva em consideração uma determinada tecnologia disponível, os recursos a serem utilizados e a finalidade em atender os desejos do consumidor. Apesar de todo o planejamento a ser realizado para o desenvolvimento de um novo produto, isso não significa que ele obterá sucesso. Além disso, ser bem-sucedido inicialmente não implica garantia de continuidade do produto no mercado (GOBE, 2004). Todo produto, durante sua vida no mercado, passa por uma série de estágios que são apresentados na Figura 2.

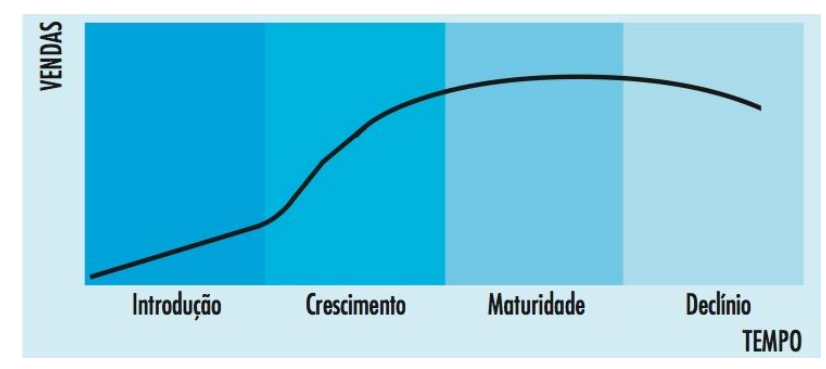

Figura 2 - Ciclo de vida do produto. (Fonte: GOBE, 2004).

No estágio introdução também conhecido como lançamento é que a empresa faz o seu maior investimento, pois, além de ter custeado todo o desenvolvimento do produto, sua produção em escala econômica e sua distribuição nos diferentes pontos de venda, faz-se necessário agora o investimento para a comunicação dele no mercado, ou seja, através da publicidade, visto que ninguém tem conhecimento de sua existência e finalidade. O principal objetivo com essa ação de marketing é despertar o interesse do consumidor/cliente pelo produto, destacando os seus atributos e os benefícios gerados. O segundo estágio do ciclo de vida do produto é chamado crescimento, nesse momento, o produto passou a ter uma rápida aceitação 
pelo mercado, e suas vendas são crescentes, gerando caixa positivo, ou lucro, na sua comercialização. O tempo de crescimento de um produto no mercado é determinado pela sua estratégia do estágio anterior e pelo investimento disponível para seu lançamento. O terceiro estágio é compreendido como maturidade, identificado como o momento da queda no crescimento das vendas, visto que a maioria dos clientes potenciais já tem conhecimento do produto ou já o adquiriu. Nesse momento, os lucros tendem a cair, tendo em vista que são necessários novos investimentos na manutenção do produto, e o crescimento das vendas não existe mais. O último estágio é o declínio, definido como a queda nas vendas e pelo desaparecimento do lucro. O produto deixa de ser procurado, o consumidor não tem mais interesse por ele ou surgiram novos produtos no mercado que atendem de maneira diferenciada as necessidades existentes por meio de novos atrativos ou de uma melhor relação custo $v s$ beneficio (GOBE, 2004, MARTINS; LAUGENI, 2005).

Todo produto quando adquirido gera certa quantidade de lixo (também chamado de resíduos sólidos urbanos (RSU)), seja pelas suas embalagens ou quando não é mais utilizado.

Esses fatores têm causado certa preocupação em relação ao meio ambiente, muitos RSU são descartados em locais inadequdos proporcionando sérios problemas ao ecossistema e a saúde humana. No Brasil, a coleta de lixo avançou, porém, cerca de 4 milhões de brasileiros não eram beneficiados pelo serviço em 2010 e consequentemente, existia o hábito de jogar o lixo doméstico em terrenos baldios (BECHARA, 2013). A Política nacional de resíduos sólidos vem como uma forma de auxiliar a todos, população e empresários, quanto a prevenção e redução desses resíduos.

A Lei n ${ }^{\circ} 12.305 / 10$, que institui a Política Nacional de Resíduos Sólidos (PNRS) contém instrumentos importantes para permitir o avanço necessário do País no enfrentamento dos principais problemas ambientais, sociais e econômicos decorrentes do manejo inadequado dos resíduos sólidos. Prevê a prevenção e a redução na geração de resíduos, tendo como proposta a prática de hábitos de consumo sustentável e um conjunto de instrumentos para propiciar o aumento da reciclagem e da reutilização dos resíduos sólidos e a destinação ambientalmente adequada dos rejeitos. De acordo com o artigo $6^{\circ}$ são princípios da Política Nacional de Resíduos Sólidos:

I - a prevenção e a precaução;

II - o poluidor-pagador e o protetor-recebedor;

III - a visão sistêmica, na gestão dos resíduos sólidos, que considere as variáveis ambiental, social, cultural, econômica, tecnológica e de saúde pública;

IV - o desenvolvimento sustentável;

V - a ecoeficiência, mediante a compatibilização entre o fornecimento, a preços competitivos, de bens e serviços qualificados que satisfaçam as necessidades humanas e tragam qualidade de vida e a redução do impacto ambiental e do consumo de recursos naturais a um nível, no mínimo, equivalente à capacidade de sustentação estimada do planeta; VI - a cooperação entre as diferentes esferas do poder público, o setor empresarial e demais segmentos da sociedade;

VII - a responsabilidade compartilhada pelo ciclo de vida dos produtos; VIII - o reconhecimento do resíduo sólido reutilizável e reciclável como um bem econômico e de valor social, gerador de trabalho e renda e promotor de cidadania; 


\section{IX - o respeito às diversidades locais e regionais; \\ $\mathrm{X}$ - o direito da sociedade à informação e ao controle social; \\ XI - a razoabilidade e a proporcionalidade (POLÍTICA NACIONAL DE RESÍDUOS SÓLIDOS, Lei n ${ }^{\circ}$ 12.305/10).}

As empresas podem praticar o desenvolvimento sustentável através da redução de emissões gasosas, líquidas ou sólidas, do reaproveitamento ou diminuição dos recursos, tanto de matérias-primas quanto recursos energéticos, ou atuando na reciclagem de resíduos inerentes ao processo, ou seja, trabalhando os conceitos dos 3R's: reduzir o desperdício de matérias primas, energia e a quantidade de lixo, mantendo um consumo mais racional, reutilizar ao máximo os diversos materiais, de forma a compartilhar com outras pessoas/empresas o que não serve mais e desenvolver atividades de recuperação, conservação e reaproveitamento do mais diversos objetos e reciclar, encaminhando materiais a um reprocesso de forma que obtenha um novo produto (SPERANDIO; GASPAR, 2009). Diante de todo contexto apresentado, pretendese nesse trabalho identificar os principais materiais utilizados como matéria-prima pelas empresas localizadas em Itatiba e região e correlacionar com as disciplinas de Tecnologia dos Materiais e Processos de Fabricação de forma a melhor contribuir com a formação dos alunos e proporcionando situações do dia a dia de uma empresa seja na identificação do material, no processo de fabricação, na resolução de problemas ou no marketing do produto.

\section{METODOLOGIA}

Antes de iniciar qualquer levantamento, esse trabalho foi submetido ao Comitê de Ética da USF e aprovado sob o número CAAE: 55009616.4.0000.5514.

A seleção das empresas foi realizada mediante contato com os discentes dos cursos de Engenharia de Produção e Engenharia Química do quarto, sexto e oitavo semestre da Universidade São Francisco do Campus de Itatiba que estagiam ou trabalham nessas empresas. Posteriormente, foram realizadas consultas aos sites das empresas e contato telefônico com o intuito de falar com o setor responsável pelo meio ambiente. Em algumas das empresas, o setor de meio ambiente era terceirizado, então foi conversado com o responsável pelo setor de segurança do trabalho, era esse o que mais tinha contato com o terceirizado, responsável pelo setor de meio ambiente. No contato com o responsável era explicado sobre o teor da pesquisa e as empresas que concordavam em participar solicitava-se o e-mail de contato, na sequência um e-mail explicando o objetivo da pesquisa foi enviado.

Inicialmente adotou-se como estratégia para o levantamento das informações, junto às empresas que aceitaram em participar da pesquisa a aplicação de um questionário contendo 30 questões (Anexo A) nos meses de outubro, novembro e dezembro de 2015. O questionário foi elaborado em conjunto entre os professores e alunos baseando na pesquisa de Delgado (2007). Para que as empresas respondessem a pesquisa, foi criada uma plataforma web com login e senha para cada empresa consultada. No entanto, essa estratégia não foi bem sucedida, apenas duas empresas participaram da pesquisa. Pensando em uma alternativa para o problema identificado, mudou-se a abordagem, para a obtenção das informações, o novo plano baseou-se na criação de um novo questionário com 22 questões (Anexo B) e aplicado de forma impressa aos discentes do curso de Engenharia de Produção da Universidade São Francisco entre os meses de Maio e Junho de 2016, que atuam no setor secundário da economia, isto é, nas indústrias de transformação, mediante o TERMO DE LIVRE CONSENTIMENTO 
ESCLARECIDO (Anexo C). Com essa mudança, houve um aumento significativo de respostas comparado à pesquisa anterior.

\section{RESULTADOS E DISCUSSÃO}

A plataforma web (Figura 3) foi criada por um aluno do curso Superior em Tecnologia de Análises e Desenvolvimento de sistemas da USF, para cada empresa contata foi criado um login e senha para o acesso a pesquisa.

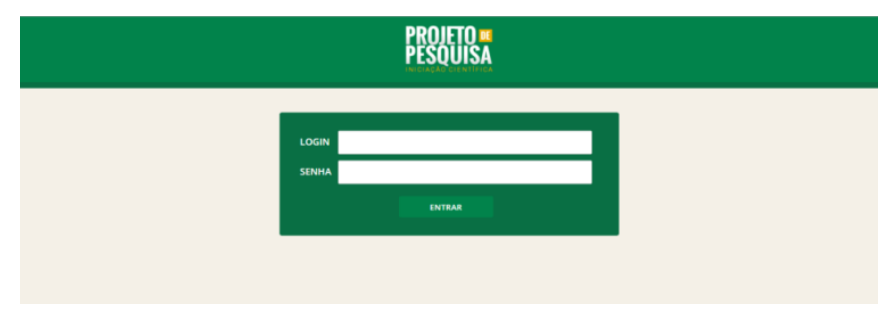

Figura 3 - Página Inicial da plataforma web. (Fonte: Próprio autor, disponível em http://www.hippodesign.com.br/usf/login).

Através da primeira estratégia, um total de 38 empresas foi listado pelos discentes dos cursos de Engenharia de Produção e Engenharia Química da Universidade São Francisco. Dessas, 20 empresas estão instaladas na cidade de Itatiba, representando 52\% das empresas. As demais estão instaladas nas cidades de Campinas, Jundiaí, Valinhos, Vinhedo, Atibaia, Louveira, Jarinu, Extrema e Sumaré, atestando a representatividade do curso nessas cidades. Das 20 empresas, 15 foram contatadas por telefone e, posteriormente por e-mail e convidadas a participarem da pesquisa. Foi realizada uma busca via internet para identificar o telefone de algumas empresas, e como resultado foi listado mais 10 empresas. Assim, um total de 30 empresas somente da cidade de Itatiba foram identificadas. Os ramos de atuação dessas empresas são apresentados na Figura 4 (A).

Percebe-se uma diversificação dos ramos de atuação das empresas listadas, todas do setor secundário da economia, ou seja, pertencentes às indústrias de transformação, com boa parte $23 \%$ incorporando o setor têxtil que, historicamente, faz parte da cidade de Itatiba e $17 \%$ no ramo metalúrgico. A empresa citada como sistemas automotivos trabalha tanto com metalurgia quanto com plástico, chama a atenção à empresa que se autodeclara como participante do ramo de reciclagem. Isto pode ser considerado uma tendência atual devido ao atendimento à Política Nacional dos Resíduos Sólidos. As empresas convidadas, inicialmente, a participarem da pesquisa pertencem aos ramos de atuação apresentados na Figura 4 (B). 


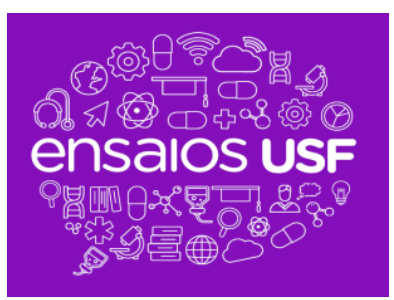

(A)

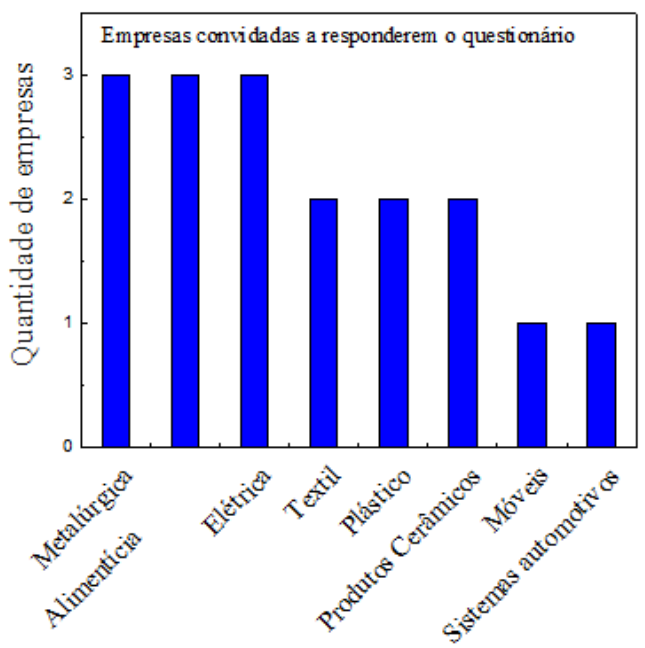

Ramo de atuacão
(B)

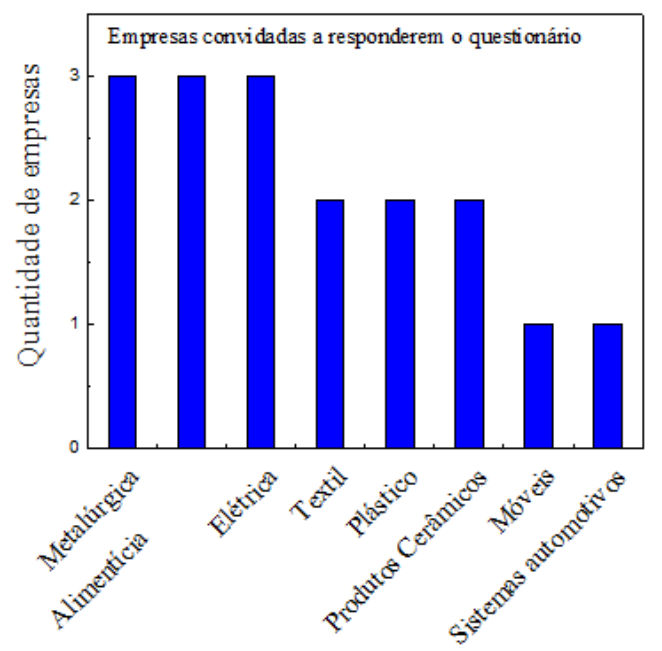

Ramo de atuação

Figura 4 - (A) Ramos de atuação das empresas de Itatiba. (B) Empresas contatadas e convidadas para participar da pesquisa. (Fonte: Próprio autor)

Como pode ser observada na Figura 4 (B) a escolha das empresas convidadas a participarem da pesquisa continha exemplares dos mais variados ramos de atuação. Entretanto, apenas duas responderam ao questionário, o que pode ter sido ocasionado por diversas razões, como período inapropriado para a pesquisa, por estar próximo da finalização do ano; incerteza econômica, política e financeira do país e despreocupação com as questões ambientais. Devido ao baixo índice de respostas, foi abordada uma nova estratégia, uma adaptação no questionário e sua aplicação aos discentes do curso de Engenharia de Produção do sétimo e nono semestre que atuam diretamente e de forma efetiva nas empresas. Após a mudança no foco da estratégia no recolhimento de informações, foi quantificado um total de 29 entrevistados que forneceram informações acerca dos materiais e questões ambientais. A Figura 5 (A) apresenta os segmentos de atuação das empresas, observa-se que não são muito diferentes comparados as empresas convidadas a responderem a pesquisa. O destaque é dado para o segmento Mecânica, essa diferença pode ser devido a grande quantidade de minério de ferro no país, assim como a proximidade geográfica de Itatiba com grandes pólos industriais do estado, além do fato de Itatiba e região estarem cercada das melhores rodovias do país, como Dom Pedro I, Anhanguera e Bandeirantes, facilitando o fluxo logístico de materiais e produtos. Entre as principais matérias-primas apontadas no questionário (Figura 5 (B)) identificam-se o alumínio, ferro e 
aço, muito utilizados na indústria mecânica, com $24 \%$ se destaca o material plástico, esse fato pode estar relacionado com o aumento de empresas recicláveis.

(A)

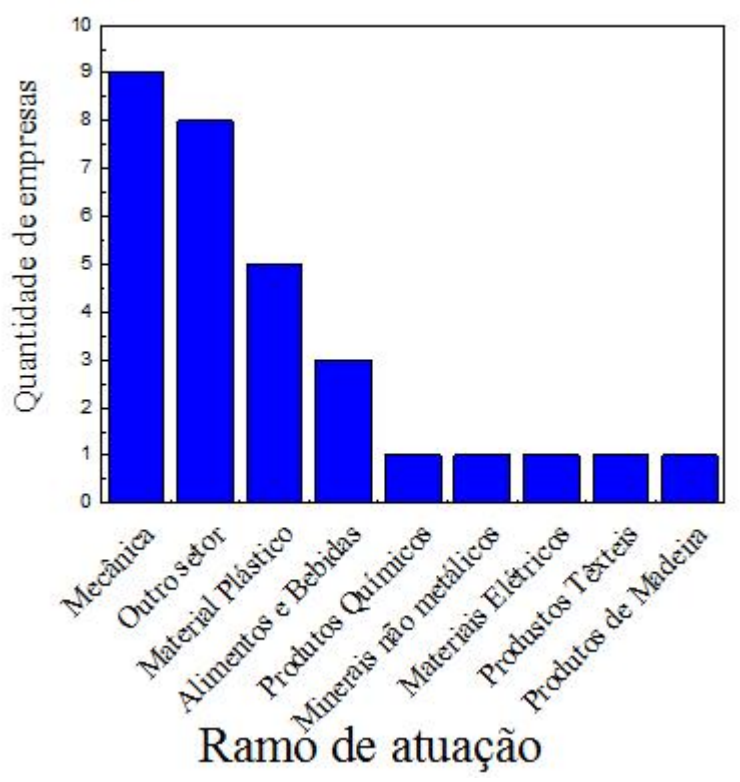

(B)

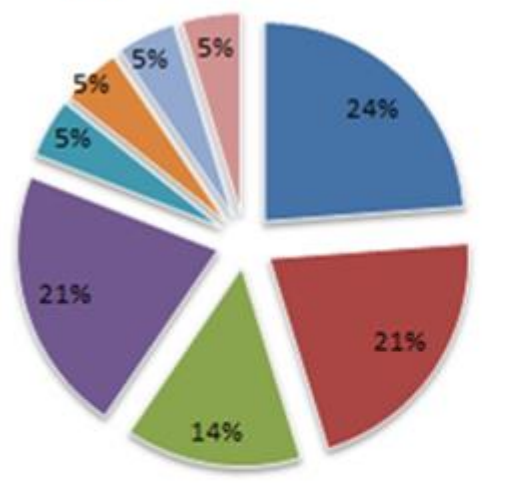

n Material Plástico

- Alumínio

a Ferro

= Aço

- Água

- Borracha

$=$ Inox

= Óleo

Figura 5 - (A) Ramos de atuação apresentados pelos discentes. (B) Relação das principais matérias-primas. (Fonte: Próprio autor).

Um dos problemas que uma empresa seja de manufatura ou prestadora de serviços enfrenta no momento atual é com relação à questão ambiental (NASCIMENTO, et al., 2013), nesse sentido faz-se necessário pensar em estratégias como, por exemplo, num planejamento de Sistema de Gestão Ambiental (SGA), entre os participantes apenas 10\% não sabiam responder e $55 \%$ apontaram que as empresas em que atuam praticam ações sustentáveis e possuem o SGA (Figura 6 (A)), é importante salientar que de fato há preocupação com o Meio Ambiente. Ainda é possível inferir que $48 \%$ da água utilizada nas empresas são apenas para o consumo e manutenção da limpeza, o que não deve ser um montante no final do mês comparando quando se usa água no processo.

Os resíduos sólidos gerados nas empresas são apresentados na Figura 7, observa-se que a os materiais ferrosos apresentaram maior índice de resposta já que o maior segmento das empresas é metalúrgico, não entanto, um fato curioso, a maioria desses resíduos é vendida como matéria-prima para outras empresas, a partir dessa ação além de aumentar seu capital contribuem com a redução do impacto ambiental devido ao descarte incorreto desses resíduos. 


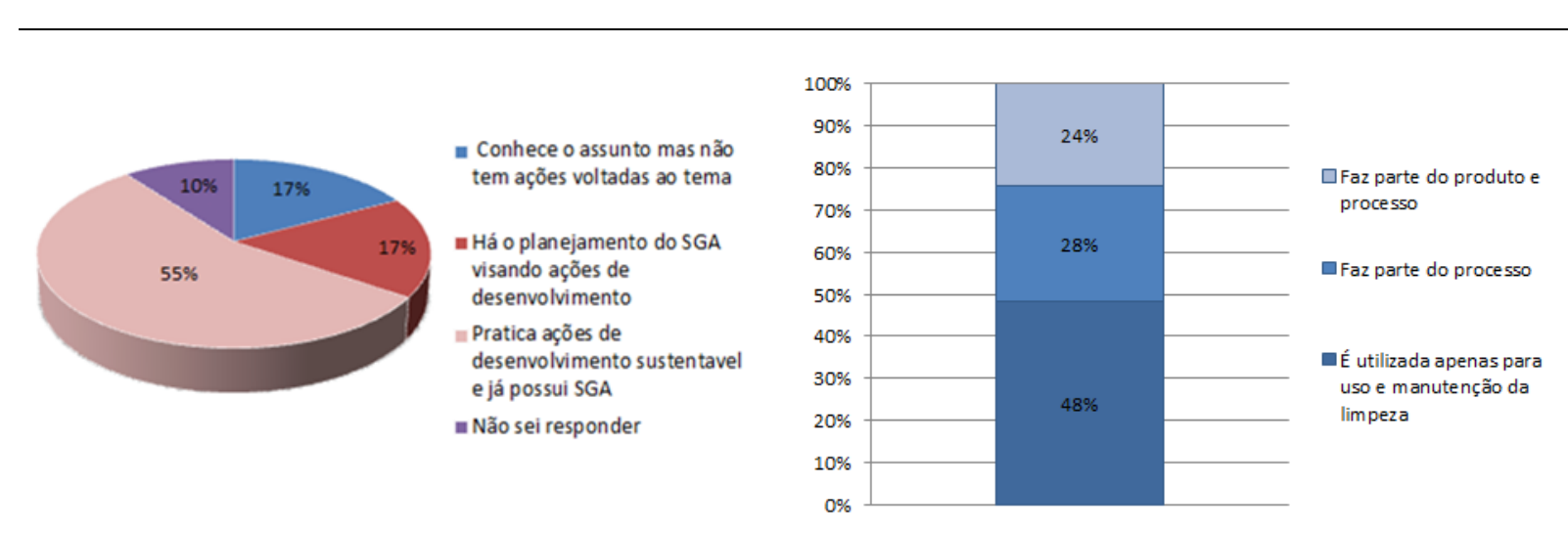

Figura 6 - (A) Ações Referentes ao desenvolvimento sustentável. (B) A respeito da água utilizada pela empresa. (Fonte: Próprio autor).

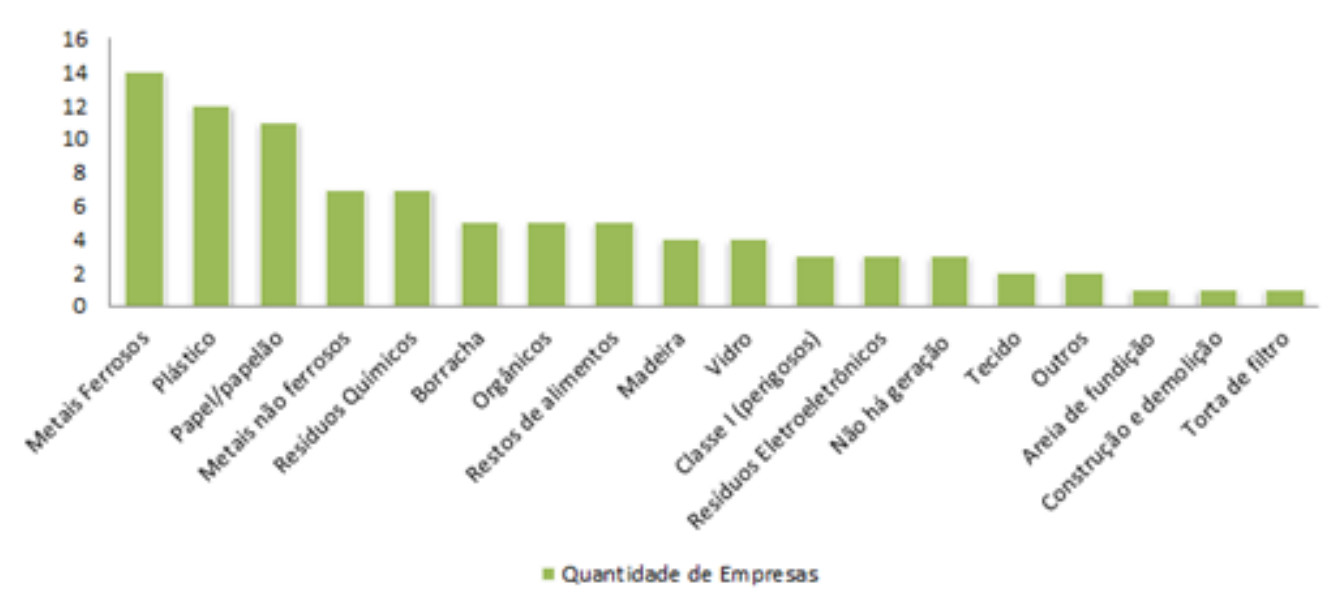

Figura 7 - Resíduos Sólidos Gerados. (Fonte: Próprio autor).

A partir das respostas apontadas pelos discentes foi possível identificar quais os materiais mais utilizados pelas empresas. Com isso, a correlação entre eles e as disciplinas Tecnologia dos Materiais e Processos de Fabricação pode se tornar mais eficaz.

\section{CONCLUSÃO}

O estudo dos materiais através das suas características físicas e químicas, assim como o seu processo de fabricação, aplicação e o seu eventual impacto ao meio ambiente é de extrema importância para que seja possível pensar e elaborar novas estratégias pensando no clico de vida do produto. Embora tenha levantado um número significativo de empresas, desenvolvido o questionário e inserido em plataforma web, os índices de respostas das empresas foram muito baixos, impossibilitando a continuidade deste trabalho. Pensando em resolver esse problema, a nova estratégia foi adaptar o questionário e aplicá-lo aos discentes do curso de Engenharia de Produção do sétimo e nono semestre. Dessa forma, foi possível obter vários padrões de resposta e correlacioná-los com nas disciplinas de Tecnologia dos Materiais e Processos de Fabricação. 


\section{AGRADECIMENTOS}

Agradecemos o Programa de Iniciação Científica, de Iniciação Tecnológica e de Extensão - PICITExt pela oportunidade de realizar o trabalho.

\section{REFERÊNCIAS}

BECHARA, E. Aspectos relevantes da política nacional de resíduos sólidos Lei no 12.305/2010/ - São Paulo: Atlas, 2013.

CABral, J. B. G.; MURPHY, C. C. A Fuel Cell, o Meio Ambiente e o Seu Carro, 2010. Disponível em: <http://www.h2brasil.com/parte-1/1-2-a-fabrica-o-do-autom-vel-aug-11-20107-08-05-am-5>. Acesso em 14 de Abril, 2018.

CALLISTER, W. Ciência e Engenharia dos Materiais: uma Introdução. 5. ed. Rio de Janeiro: LTC, 534 p., 2002

CAO, G. Nanostructures \& Nanomaterials. Imperial College Press: London, 433 p. 2004.

CIPRIANO, T.; KNOTTS. G.; LAUDARI. A.; BIANCHI, R. C.; ALVES, W. A.; GUHA. S. Bioinspired Peptide Nanostructures for Organic Field-Effect Transistors. ACS Appl. Mater. Interfaces, v. 6, (23), 21408-21415, 2014.

CNE/CES. Conselho Nacional De Educação Câmara De Educação Superior. Resolução CNE/CES 11, de 11 de março de 2002. Disponível em: < http://portal.mec.gov.br/cne/arquivos/pdf/CES112002.pdf>. Acesso em 15 de Abril, 2018.

DELGADO, JORGE JUAN SOTO. Desenvolvimento sustentável e a indústria química brasileira: análise das posturas empresariais e proposta de desdobramento das suas estratégias. 2007. 212 p. Tese (Doutorado em Ciência em Planejamento Energético) - Programa de PósGraduação em Engenharia, Universidade Federal do Rio de Janeiro.

FIRJAM, IFDM e Indicadores para Itatiba, 2010. Disponível em: $<$ http://www.firjan.org.br/ifdm/consulta-ao-indice/consulta-ao-indicegrafico.htm? UF=SP\&IdCidade=352340\&Indicador=1\&Ano=2010>. Acesso em: 14 de abril, 2018.

GOBE, A. C.; MOREIRA, J. C. T.; PEREZ, M. C.; CARRAMENHA, P. R. C.; PASQUALE, P. P. Gerência de produtos. São Paulo: Saraiva, 2004. 258 p.

INTERRANTE, L. V.; HAMPDEN-SMITH, M. J. Chemistry of Advanced Materials: An Overview, Wiley-VCH: New York, 1998

MARTINS, P. G; LAUGENI, F. P. Administração da produção. Saraiva: 2005. 
NASCIMENTO, L. S.; NASCIMENTO, P. F. P.; PEREIRA, K. I. A.; SOARES, SOUZA, D. C.; M. C. L. Planejamento de um Sistema de Gestão Ambiental: Estudo de Caso em uma Microempresa Moveleira. XXXIII Encontro Nacional de Engenharia de Produção (Enegep), 2013.

POLITICA NACIONAL DE RESIDUOS SOLIDOS. Política Nacional de Resíduos Sólidos. Disponível em: < http://www.mma.gov.br/pol\%C3\%ADtica-de-res\%C3\%ADduoss\%C3\%B3lidos > . Acesso em 15 abril, 2018.

PPC. Projeto Pedagógico Curso de Engenharia de Produção. Universidade São Francisco (USF), v. 1, 2013.

SPERANDIO, S. A.; GASPAR, M. A. Gestão Socioambiental em Empresas Industriais. Rev. Adm. UFSM, Santa Maria, v. 2, n. 1, p. 21-40, jan./abr. 2009.

VAN VLACK, L. H. Princípios de Ciência e Tecnologia dos Materiais. 11. ed. Rio de Janeiro: Campus, 567 p., 1984.

Publicado em 17/12/2019 


\section{ANEXO}

\section{A - PRIMEIRO QUESTIONÁRIO}

1 - Número de colaboradores:
a) 1 a 99 colaboradores
b) 100 a 499 colaboradores
c) Acima de 500 colaboradores.

2 - Formação de Capital
a) empresa de origem nacional
b) empresa de origem multinacional

\section{3 - Segmento}
a) alimentos e bebidas
b) produtos químicos de base
c) produtos químicos de uso final
d) metal-mecânica
e) borracha e/ou material plástico
f) celulose, papel e produtos de papel
g) minerais não-metálicos/cerâmicas
h) materiais elétricos, de informática, eletrônicos ou ópticos
i) produtos têxteis
j) móveis e produtos de madeira
k) outro setor

4 - Listar cinco matérias-primas principais:

5 - Listar cinco resíduos (gasosos, líquidos, sólidos ou linhas de reciclo)

6 - Caracterização do respondente - Posição:
a) Diretoria
b) Gerência
c) Supervisão/coordenação
d) Líder
e) Efetivo da área
f) outros

7 - Área de atuação:
a) Diretoria geral
b) Apoio de Planejamento
c) Apoio em Meio Ambiente ou Responsabilidade Social
d) Liderança de Linha (produção e comercialização)

8 - Formação
a) Primeiro grau
b) Segundo grau 

c) Ensino Técnico
d) Universitário
e) Pós-Graduado

9 - Nível de ações referentes ao desenvolvimento sustentável na empresa:

a) a empresa não tem ações de desenvolvimento sustentável.

b) a empresa conhece o assunto mais não tem ações voltadas ao tema.

c) a empresa está planejando a implantação de um sistema de gestão ambiental (SGA) visando ações de desenvolvimento sustentável.

d) a empresa pratica amplamente ações de desenvolvimento sustentável e possui SGA já implantado.

10 - A respeito da fonte de energia elétrica utilizada pela empresa:

a) é obtida integralmente da rede concessionária.

b) utiliza parte proveniente de gerador próprio.

11 - A respeito do sistema de utilidades: Existe caldeira e qual o tipo de energia utilizado?

a) Existe, lenha

b) Existe, óleo BPF

c) Existe, energia elétrica

d) Existe, gás

e) Não utiliza caldeira

12 - A respeito do sistema de utilidades: Existem os equipamentos listados a seguir?
a) Existem compressores
b) Existem torres de resfriamento
c) Existem chillers
d) Existe boiler

13 - A respeito consumo de energia elétrica, existe plano de ação para sua diminuição:
a) não tem plano de ação.
b) tem plano, mas não está sendo eficaz.
c) tem plano de ação eficaz.

14 - A respeito da origem da água na empresa:
a) é obtida integralmente da rede concessionária.
b) é proveniente de poço artesiano.
c) é proveniente de rios ou represa.

15 - A respeito da água utilizada pela empresa:
a) Faz parte do produto.
b) Faz parte do processo.
c) Faz parte do produto e do processo.
d) É utilizada apenas para uso manutenção da limpeza da empresa.

16 - A respeito do tratamento da água de entrada utilizada pela empresa:

a) Recebe tratamento em ETA própria. 
b) Não recebe tratamento.

17 - A respeito do tratamento da água da saída utilizada pela empresa:

a) É encaminhada para a rede de esgoto da concessionária.

b) Recebe tratamento em ETE própria e é reutilizada pela empresa.

c) Recebe tratamento em ETE própria e é descartada para o ambiente.

18 - A respeito consumo de água, existe plano de ação para sua diminuição:

a) não tem plano de ação.

b) tem plano, mas não está sendo eficaz.

c) tem plano de ação eficaz.

19 - A respeito das emissões gasosas, são gerados os seguintes gases:

a) Gás carbônico $\left(\mathrm{CO}_{2}\right)$

b) Gás metano $\left(\mathrm{CH}_{4}\right)$

c) $\mathrm{CFCs}$

d) $\mathrm{NO}_{\mathrm{x}}$

e) $\mathrm{SO}_{\mathrm{x}}$

f) $\mathrm{VOCs}$

g) A empresa não utiliza nenhum processo de queima e não produz nenhuma emissão gasosa

20 - A respeito da existência dos diversos tipos de equipamentos de controle da poluição de ar:

a) Existem Filtros de Manga

b) Existem Coletores Inerciais ou Gravitacionais

c) Existem Coletores Úmidos

d) Existem Ciclones

e) Existem Pós-queimadores

f) Existem Precipitadores Eletrostáticos

g) Não existem equipamentos com essa finalidade.

21 - Assinale os tipos de resíduos sólidos gerados pela empresa:
a) Areia de fundição
b) Borracha
c) Classe I (Perigosos)
d) Construção e Demolição
e) Madeira
f) Metais Ferrosos
g) Metais Não Ferrosos
h) Orgânicos
i) Papel/Papelão
j) Plástico
k) Resíduos Eletroeletrônicos
1) Resíduos Químicos
m) Restos de alimentos
n) Vidro
o) Tecido 

p) Torta de filtro
q) Outros
r) Não há geração de resíduos sólidos

22 - Qual é o principal destino dos resíduos sólidos produzidos pela empresa:
a) Incineração
b) Aterro sanitário
c) É reaproveitado com matéria-prima
d) É vendido como matéria-prima para outras empresas

23 - Caso sua empresa tenha desenvolvido recentemente projetos visando melhoria dos seus principais indicadores ambientais, assinale a alternativa que aponta o principal retorno causado pela implantação desse projeto.

a) Retorno de imagem geral da empresa e da marca

b) Retorno econômico

c) Melhoria de relação interna dos colaboradores e/ou com a sociedade

d) Aumento de portfólio de clientes

e) Melhoria do desempenho econômico, ambiental e social de forma equilibrada

f) Redução do impacto ambiental causado.

24 - Liste os indicadores ambientais utilizados em sua empresa e marque o nível correspondente de melhoria alcançados nos últimos cinco anos (considere que houve melhoria quando os resultados alcançados seguiram a tendência planejada pela empresa).

Alguns exemplos de indicadores ambientais: consumo de energia (absoluto ou relativo à produção); consumo de energia por tipo de fonte (hidroelétrica, gás, eólica...); consumo de água (absoluto ou relativo à produção); consumo de matéria-prima (absoluto ou relativo à produção); emissões gasosas totais (absolutas, relativas à produção); emissões gasosas do efeito estufa

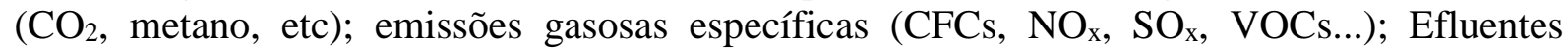
líquidos totais (absoluto, relativo à produção carga de poluição); carga de poluição em efluentes líquidos (DQO, DBO, poluente específico); resíduos sólidos, líquidos ou pastosos (absoluto, relativo à produção, por periculosidade); nível de reuso de água; destinação de resíduos (reuso, reciclagem, aterro, incineração...); ruído ambiental à comunidade; qualidade do ar sob influência do empreendimento, nível de reuso ou reciclagem de materiais (metais, papel, plásticos...); nível de atendimento dos requisitos básicos legais ambientais; número de registros de multas ou infrações de órgãos ambientais, número de acidentes envolvendo o uso do produto ou serviço; recursos direcionados a investimentos em melhorias ambientais (absolutos ou relativos ao total, ao faturamento...); recursos destinados ao custeio do controle ambiental (tratamento de emissões, efluentes ou resíduos); recursos destinados à capacitação nas questões ambientais (tempo ou econômicos).

\begin{tabular}{|l|l|}
\hline Item & $\begin{array}{l}\text { Nível aproximado de melhoria alcançado nos últimos 5 } \\
\text { anos }\end{array}$ \\
\hline
\end{tabular}


http://ensaios.usf.edu.br

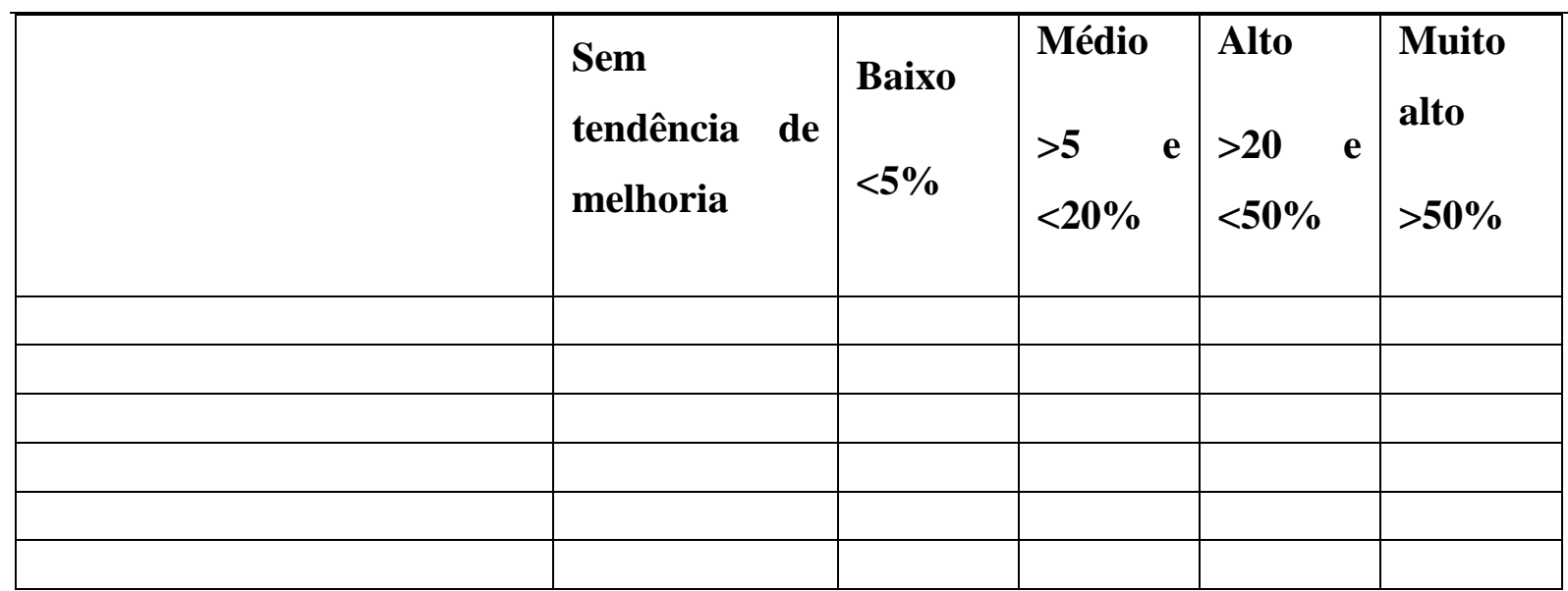

25 - Liste as principais dificuldades apresentadas hoje pela empresa no se que refere às melhorias das questões ambientais.

26 - Há interesse por parte da organização de realizar um projeto em colaboração a fim de sanar essas dificuldades?

a) $\mathrm{Sim}$

b) Não

27 - Nome da empresa

28 - Endereço completo da empresa

29 - Nome do respondente

30 - e-mail do respondente

\section{B - SEGUNDO QUESTIONÁRIO}

1 - Número de colaboradores:

a) 1 a 99 colaboradores

b) 100 a 499 colaboradores

c) Acima de 500 colaboradores.

2 - Formação de Capital

a) empresa de origem nacional

b) empresa de origem multinacional

3 - Segmento

a) alimentos e bebidas

b) produtos químicos de base

c) produtos químicos de uso final

d) metal-mecânica

e) borracha e/ou material plástico

f) celulose, papel e produtos de papel 

g) minerais não-metálicos/cerâmicas
h) materiais elétricos, de informática, eletrônicos ou ópticos
i) produtos têxteis
j) móveis e produtos de madeira
k) outro setor

4 - Listar cinco matérias-primas principais:

5 - Listar cinco resíduos (gasosos, líquidos, sólidos ou linhas de reciclo)

6 - Nível de ações referentes ao desenvolvimento sustentável na empresa:
a) a empresa não tem ações de desenvolvimento sustentável.
b) a empresa conhece o assunto mais não tem ações voltadas ao tema.
c) a empresa está planejando a implantação de um sistema de gestão ambiental (SGA) visando ações de desenvolvimento sustentável.
d) a empresa pratica amplamente ações de desenvolvimento sustentável e possui SGA já implantado.

7 - A respeito da fonte de energia elétrica utilizada pela empresa:
a) é obtida integralmente da rede concessionária.
b) utiliza parte proveniente de gerador próprio.

8 - A respeito do sistema de utilidades: Existe caldeira e qual o tipo de energia utilizado?
a) Existe, lenha
b) Existe, óleo BPF
c) Existe, energia elétrica
d) Existe, gás
e) Não utiliza caldeira

9 - A respeito consumo de energia elétrica, existe plano de ação para sua diminuição:
a) não tem plano de ação.
b) tem plano, mas não está sendo eficaz.
c) tem plano de ação eficaz.

10 - A respeito da origem da água na empresa:
a) é obtida integralmente da rede concessionária.
b) é proveniente de poço artesiano.
c) é proveniente de rios ou represa.

11 - A respeito da água utilizada pela empresa:
a) Faz parte do produto.
b) Faz parte do processo.
c) Faz parte do produto e do processo.
d) É utilizada apenas para o uso e manutenção da limpeza da empresa.

12 - A respeito do tratamento da água de entrada utilizada pela empresa:

a) Recebe tratamento em ETA própria. 
b) Não recebe tratamento.

13 - A respeito do tratamento da água da saída utilizada pela empresa:

a) É encaminhada para a rede de esgoto da concessionária.

b) Recebe tratamento em ETE própria e é reutilizada pela empresa.

c) Recebe tratamento em ETE própria e é descartada para o ambiente.

14 - A respeito consumo de água, existe plano de ação para sua diminuição:

a) não tem plano de ação.

b) tem plano, mas não está sendo eficaz.

c) tem plano de ação eficaz.

15 - A respeito das emissões gasosas, são gerados os seguintes gases:

a) Gás carbônico $\left(\mathrm{CO}_{2}\right)$

b) Gás metano $\left(\mathrm{CH}_{4}\right)$

c) $\mathrm{CFCs}$

d) $\mathrm{NO}_{\mathrm{x}}$

e) $\mathrm{SO}_{\mathrm{x}}$

f) $\mathrm{VOCs}$

g) A empresa não utiliza nenhum processo de queima e não produz nenhuma emissão gasosa

16 - Assinale os tipos de resíduos sólidos gerados pela empresa:

a) Areia de fundição

b) Borracha

c) Classe I (Perigosos)

d) Construção e Demolição

e) Madeira

f) Metais Ferrosos

g) Metais Não Ferrosos

h) Orgânicos

i) Papel/Papelão

j) Plástico

k) Resíduos Eletroeletrônicos

1) Resíduos Químicos

m) Restos de alimentos

n) Vidro

o) Tecido

p) Torta de filtro

q) Outros

r) Não há geração de resíduos sólidos

17 - Qual é o principal destino dos resíduos sólidos produzidos pela empresa:
a) Incineração
b) Aterro sanitário
c) É reaproveitado com matéria-prima
d) É vendido como matéria-prima para outras empresas 
18 - Caso sua empresa tenha desenvolvido recentemente projetos visando melhoria dos seus principais indicadores ambientais, assinale a alternativa que aponta o principal retorno causado pela implantação desse projeto.

a) Retorno de imagem geral da empresa e da marca

b) Retorno econômico

c) Melhoria de relação interna dos colaboradores e/ou com a sociedade

d) Aumento de portfólio de clientes

e) Melhoria do desempenho econômico, ambiental e social de forma equilibrada

f) Redução do impacto ambiental causado.

19 - Liste as principais dificuldades apresentadas hoje pela empresa no se que refere à melhoria das questões ambientais.

20 - Há interesse por parte da organização de realizar um projeto em colaboração a fim de sanar essas dificuldades?

a) $\mathrm{Sim}$

b) Não

21 - Nome da empresa

22 - Nome do respondente

23 - e-mail do respondente

\section{C - TERMO DE LIVRE CONSENTIMENTO ESCLARECIDO}

Investigação dos Materiais Utilizados como Matéria-Prima nas Indústrias Localizadas em Itatiba e Região Visando maior contextualização dos conteúdos da Disciplina

Tecnologia dos Materiais e Processos de Fabricação do Curso Engenharia de Produção da Universidade São Francisco.

$\mathrm{Eu}$,

$\mathrm{RG}$ , abaixo assinado, dou meu consentimento livre e esclarecido para participar como voluntário do projeto de pesquisa supracitado, sob a responsabilidade do(s) pesquisador(es), Roberta Martins da Costa Bianchi, Elaine Cristina Marques e Felipe Gois da Silva do Curso de Engenharia de Produção da Universidade São Francisco

Assinando este Termo de Consentimento estou ciente de que:

1 - O objetivo da pesquisa é identificar as variáveis externas que agem sobre as empresas no sentido de incentivar às melhorias ambientais; identificar a motivação das empresas no engajamento relacionado às técnicas que permitam crescimento com desenvolvimento sustentável; Levantar e analisar as dificuldades encontradas pelas empresas no que se refere às melhorias ambientais em seus processos;

2- Durante o estudo será aplicado um questionário prévio visando o levantamento das principais ações e principais indicadores de ecoefíciência ambientais das empresas da região de Itatiba. $\mathrm{O}$ 
questionário será aplicado aos alunos do sétimo e nono semestre do curso de Engenharia de Produção. O tempo estimado para responder à pesquisa é de 20 minutos;

3 - Obtive todas as informações necessárias para poder decidir conscientemente sobre a minha participação na referida pesquisa;

4- A resposta a este (s) instrumento(s)/ procedimento(s) não causam riscos conhecidos à minha saúde física e mental;

5 - Estou livre para interromper a qualquer momento minha participação na pesquisa, o que não me causará nenhum prejuízo;

6 - Meus dados pessoais serão mantidos em sigilo e os resultados gerais obtidos na pesquisa serão utilizados apenas para alcançar os objetivos do trabalho, expostos acima, incluída sua publicação na literatura científica especializada;

7 - Poderei contatar o Comitê de Ética em Pesquisa da Universidade São Francisco para apresentar recursos ou reclamações em relação à pesquisa pelo telefone: 11 - 24548981;

8 - Poderei entrar em contato com o responsável pelo estudo, Profa. Elaine Cristina Marques (11) 4534-8031 e Profa. Roberta Martins da Costa Bianchi (11) 97368-3064, sempre que julgar necessário pelos telefones acima disponíveis;

9- Este Termo de Consentimento é feito em duas vias, sendo que uma permanecerá em meu poder e outra com o pesquisador responsável.

Local,

Assinatura do Sujeito de Pesquisa ou Responsável:

Assinatura do Pesquisador Responsável: 